\title{
Metabolism of pyrene through phthalic acid pathway by enriched bacterial consortium composed of Pseudomonas, Burkholderia, and Rhodococcus (PBR)
}

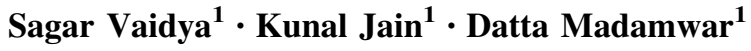

Received: 26 July 2016/Accepted: 2 January 2017/Published online: 11 April 2017

(C) The Author(s) 2017. This article is an open access publication

\begin{abstract}
Polycyclic aromatic hydrocarbons (PAHs) are highly recalcitrant compounds due to their high hydrophobicity and tendency to partition in organic phase of soils. Pyrene is a high-molecular weight PAH, which has human health concerns. In the present study, a bacterial consortium, PBR, was developed from a long-term polluted site, viz., Amlakhadi, Ankleshwar, Gujarat, for effective degradation of pyrene. The consortium effectively metabolized pyrene as a sole source of carbon and energy. The consortium comprised three bacterial species, Pseudomonas sp. ASDP1, Burkholderia sp. ASDP2, and Rhodococcus sp. ASDP3. The maximum growth rate of consortium was $0.060 / \mathrm{h}$ and the maximum pyrene degradation rate was $16 \mathrm{mg} / \mathrm{l} / \mathrm{day}$. The organic and inorganic nutrients along with different surfactants did not affect pyrene degradation, but degradation rate moderately increased in the presence of sodium succinate. The significant characteristic of the consortium was that it possessed an ability to degrade six other hydrocarbons, both independently and simultaneously at $37{ }^{\circ} \mathrm{C}$, in BHM (pH 7.0) under shaking conditions $(150 \mathrm{rpm})$ and it showed resistance towards mercury at $10 \mathrm{mM}$ concentration.
\end{abstract}

Electronic supplementary material The online version of this article (doi:10.1007/s13205-017-0598-8) contains supplementary material, which is available to authorized users.

Datta Madamwar

datta_madamwar@yahoo.com

Sagar Vaidya

sagarvaidya207@gmail.com

1 Environmental Genomics and Proteomics Lab, UGC Centre of Advanced Study, P. G. Department of Biosciences, Sardar Patel University, Satellite Campus, Vadtal Road, Bakrol, Anand, Gujarat 388 315, India
Phthalic acid as one of the intermediates during pyrene degradation was detected through high-performance liquid chromatography (HPLC). The efficiency of consortium for pyrene degradation was validated in simulated microcosms' study, which indicated that $99 \%$ of pyrene was metabolized by the consortium under ambient conditions.

Keywords Pyrene - Sodium succinate $\cdot$ Heavy metals . Phthalic acid · Bioremediation · Enrichment technique

\section{Introduction}

Polycyclic aromatic hydrocarbons (PAHs) are ubiquitous compounds present in the environment. Their origin in the environment may be attributed to extensive anthropogenic activities like industrialization, incomplete combustion of fossil fuels and oil spills or natural phenomena like wood fires, volcano eruptions and natural underwater oil spills (Juhasz and Naidu 2000; Atlas and Hazen 2011). PAHs are considered as priority pollutants by the US Environmental Protection Agency (USEPA). They persist in the environment for a long time because of the sequestration in sediment particles' micropores and thus remain out of reach of microbial degradation. They are also concerned with human health because many PAHs are mutagenic, carcinogenic and teratogenic (Haritash and Kaushik 2009; Kumar et al. 2011).

Pyrene is high-molecular weight (HMW) PAH having very high hydrophobicity and because of its high octanol:water partition coefficient, there are relatively less reports of efficient degradation of this compound by microorganisms, though many efforts have been made by several investigators. In addition, few studies have reported on the utilization of these compounds as a sole carbon 
source (Bacosa and Inoue 2015; Ghosh et al. 2014; Ho et al. 2000; Wang et al. 2008). There are reports of degradation of pyrene by pure cultures and consortia developed from various origins like petroleum sludge, oil spill sites or other petroleum products contaminated sites. The isolated organisms may be from the Actinomycetes phylum (Mycobacterium sp.) or Proteobacteria (Pseudomonas sp., Burkholderia sp., etc.). But these are not very efficient degraders of HMW PAHs like pyrene. Bacosa et al. (2013) developed six consortia from sediment mainly consisting of different species of Pseudomonas and Burkholderia capable of degrading various PAHs. Availability of extra carbon or nitrogen sources may be limiting factor or the presence of toxic compounds may retard the degradation. So it is very useful to develop a versatile consortium that can degrade pyrene in the presence of other pollutants with their simultaneous degradation, since Amlakhadi canal received mixed pollutants from different surrounding industries (Patel et al. 2012a; Kathuria 2007).

The present study is focused on the development of efficient microbial consortium from the long-term polluted soil sediments of the Amlakhadi canal, Ankleshwar, which is the tributary of the Narmada River and polluted by extensive discharge of effluents from industries of the Ankleshwar Industrial Estate. Optimization of physicochemical parameters, effects of other additives and surfactants and effect of other hydrocarbons and heavy metals were other significant objectives. The most important objective of the study is a simultaneous degradation of mixture of PAHs (fluoranthene, pyrene, naphthalene, chrysene and phenanthrene) and related hydrocarbons (benzene, toluene and xylene) by developed consortium in simulated microcosms. Thus, study provides an important pace for the further bioremediation process like macrocosm study or reactor scale study.

\section{Materials and methods}

\section{Media and chemicals}

Bushnell-Haas broth (BHB), nutrient broth and nutrient agar were purchased from Himedia (Mumbai, India). All chemicals used in the study were of analytical and HPLC grade. Pyrene was purchased from Sigma-Aldrich ${ }^{\circledR}$ (Bellefonte, Pennsylvania, USA) with $99 \%$ purity.

\section{Development of microbial consortium PBR for degradation of test PAHs}

Polluted sediment samples were collected from Amlakhadi canal, Ankleshwar, Gujarat. The microbial consortium for the degradation of pyrene was developed by the culture enrichment method. Ten grams of sediment samples inoculated in $200 \mathrm{ml}$ BHB medium amended with $1000 \mathrm{ppm}$ of pyrene (from a stock solution of 50,000 ppm, filter sterilized by $0.2 \mu \mathrm{m}$ nylon filters) and incubated under shaking conditions $(150 \mathrm{rpm})$ at $37{ }^{\circ} \mathrm{C}$ for nearly 15 days. After 15 days the content of the flask was centrifuged at $200 \times g$ for $3 \mathrm{~min}$ to discard the sample debris. Ten to fifteen milliliters supernatant was inoculated into the fresh BHB amended with 1000 ppm of pyrene and continued incubation under shaking conditions $37{ }^{\circ} \mathrm{C}$ for another 15 days.

After subsequent incubation of 15 days the content of flasks was again centrifuged at $11,000 \times g \mathrm{rpm}$ for $5 \mathrm{~min}$ to harvest the cells. The cells were re-suspended in minimal quantity of sterile distilled water and inoculated in fresh BHB containing 1000 ppm of pyrene. Thus, after repeated sub-culturing of more than 25 times in minimal medium without any nutritional additives and pyrene provided as sole carbon source, consistent degradation of pyrene with stable growth of the consortium was observed. Further, the degradation of pyrene was observed on Bushnell-Haas agar medium spread with $50 \mu \mathrm{l}$ of stock solution of pyrene. Different dilutions of the consortium were spread on the solid media spiked with pyrene. After incubation of 15 days at $37{ }^{\circ} \mathrm{C}$, Bushnell-Haas agar plates were checked for degradation of pyrene by observing zone of clearance around the colonies. The grown organisms were purified by streaking and regular transfers on solid agar plates.

\section{Characterization of microbial consortium}

The enriched developed consortium was serially diluted and spread on Nutrient agar, Bushnell-Haas agar, BushnellHaas agar amended with 1000 ppm of pyrene and incubated for 1-8 days at various temperatures. Discrete colonies with distinctive morphology were further screened to pure cultures to enumerate the bacteria present in the consortium. Identification of bacterial isolates was performed using extracting genomic DNA from each pure culture using standard protocol of (Ausubel et al. 1997). $16 \mathrm{~S}$ rRNA gene was amplified by eubacterial universal primers $8 \mathrm{~F}$ and $1492 \mathrm{R}$ as described in (Desai and Madamwar 2007). The purified amplified product was sequenced using automated ABI 3500 Genetic Analyzer (Thermo Scientific, ABI, USA). Full length of 16S rRNA gene was analyzed by the BLAST tool at NCBI server to identify the bacteria.

\section{Development of Inoculum, degradation conditions and preparation of samples for HPLC}

Consortium PBR was grown in BHB amended with $1000 \mathrm{ppm}$ of pyrene under shaking conditions (150 rpm) at 
$37{ }^{\circ} \mathrm{C}$. Five percent (v/v) of this grown consortium was used as inoculum for further studies. The detailed method has been provided in the Supplementary Information.

The pyrene degradation experiments were conducted in BHM medium amended with $100 \mathrm{ppm}$ of pyrene under shaking conditions of $150 \mathrm{rpm}$ at $37^{\circ} \mathrm{C}$. The PAHs degradation efficiency of consortium PBR was studied by extracting the entire content $(100 \mathrm{ml})$ of the flask and its degraded products in $20 \mathrm{ml}$ of dichloromethane by incubating the mixture under shaking condition at $150 \mathrm{rpm}$ for $1 \mathrm{~h}$ followed by separation of aqueous and organic phases under static condition. The $500 \mu \mathrm{l}$ of separated organic phase (i.e. dichloromethane) collected in fresh microfuge and the solvent was evaporated under vacuum using SpeedVac (Thermo Electron Corporation, Waltham, MA) and the dried content was re-suspended in $1 \mathrm{ml} 70 \%$ acetonitrile. This prepared sample also diluted by $70 \%$ acetonitrile as the pyrene concentration will be in range of $10 \pm 5$ ppm to compare it with standard of 10 ppm pyrene. HPLC analysis was performed using Prominence LC system (Shimadzu, Japan), on Pursuit $3 \mathrm{PAH} \mathrm{C}_{18}$ reverse phase column (100 mm $\times 4.6 \mathrm{~mm}, 3 \mu \mathrm{m})$ (Agilent, USA), under ambient conditions, with acetonitrile:water (70:30, $\mathrm{v} / \mathrm{v}$ ) as eluent and isocratic flow rate of $1 \mathrm{ml} / \mathrm{min}$. The standards and degraded products were detected at $254 \mathrm{~nm}$ with a Photo Diode Array Detector.

\section{Study of auxiliary nutrient and environmental parameters}

For the effective degradation of pyrene by consortium PBR, several parameters were studied and optimized.

\section{Effect of supplementary co-substrates}

For enhancing the degradation potential of consortium PBR, BHM was supplemented with peptone, yeast extract, sodium succinate, ammonium nitrate $(0.1 \%$, w/v) or glucose $(2.0 \%, \mathrm{w} / \mathrm{v})$ and intermediates such as phthalic acid and salicylic acid (20 g/L) along with $100 \mathrm{ppm}$ of pyrene. Uninoculated media with the respective co-substrates amended with $100 \mathrm{ppm}$ of pyrene were served as abiotic controls. Another set of control experiments was performed with only BHB amended with 100 ppm of pyrene, inoculated with $5 \%$ of consortium PBR. All experiments were conducted under shaking conditions of $150 \mathrm{rpm}$ at $37{ }^{\circ} \mathrm{C}$, $\mathrm{pH}$ of 7.0 (unless specified) in triplicates.

\section{Effect of environmental conditions}

Different environmental factors viz. $\mathrm{pH}$ (5.0-9.0), temperature $\left(30-50{ }^{\circ} \mathrm{C}\right)$, dissolved oxygen concentration with respect to shaking speed [0 (static), 50, 100 and $150 \mathrm{rpm}$ ], initial pyrene concentrations (100-4000 ppm), presence of different hydrocarbons [fluoranthene, phenanthrene and naphthalene $(100 \mathrm{ppm})]$ other aromatic compounds [benzene, toluene and xylene $(0.1 \%, w / v)]$, heavy metals at different concentrations [mercury $(\mathrm{Hg})$, lead $(\mathrm{Pb})$, chromium $(\mathrm{Cr})$, cadmium $(\mathrm{Cd})$ and zinc $(\mathrm{Zn})$ at 1,5 and $10 \mathrm{mM}$ concentrations] surfactants CTAB (Cetyl-trimethyl ammonium bromide), SDS (sodium dodecyl sulfate), Tween-80 and Triton-X-100 (0.02\% w/v and v/v) were studied to observed the variable effect on pyrene degradation by the consortium PBR.

The $\mu_{\max }, K_{S}$ and $q_{\max }$ were obtained from the exponential growth phase and degradation rate (while studying the initial substrate concentration) using the Monod equation as described in Ghosh et al. (2014) and Okpokwasili and Nweke (2005).

\section{Microcosm study}

Microcosm study was performed to assess the potential of the developed consortium PBR for PAHs degradation in soil systems. In the study, microcosm experiments were modified from the method of Pathak et al. (2009, 2011). Since the soil sediments at Amlakhadi canal are completely submerged into the water, so as to mimic the natural environment, $50 \mathrm{~g}$ of pollutes and non-polluted soil samples were added in $100 \mathrm{ml}$ of sterile water supplemented with BHM and inoculated with $5 \times 10^{7}$ cells from exponential phase consortium PBR. Twelve different sets of experiments were conducted in triplicates as mentioned in Table 1. The experiments were performed for seven days, samples were withdrawn at third and seventh day, where $100 \mathrm{ml}$ content was extracted in $20 \mathrm{ml}$ of $\mathrm{n}$-hexane and was mixed with $20 \mathrm{ml} \mathrm{n}$-hexane and agitated on shaker at $120 \mathrm{rpm}$ for $15 \mathrm{~min}$. The mixture was allowed to settle further 10-20 min and nearly whole content $(20 \mathrm{ml})$ of $n$ hexane was collected in fresh tube. The content was diluted to being the metabolite concentration in the of $10 \mathrm{ppm}$ and degradation was measured spectrophotometrically against the blank of n-hexane using Double Beam Specord ${ }^{\circledR} 210$ BU UV-vis spectrophotometer (Analytica Jena AG, Germany) in spectral range of 190-500 nm.

\section{Results and discussion}

Pyrene is a high-molecular weight polycyclic aromatic hydrocarbon having low water solubility $(0.12-0.18 \mathrm{mg} / \mathrm{L})$ which, therefore, tends to sequester in the sediments. Hence, there are relatively very less reports on efficient microbial degradation of pyrene. The present study demonstrated the development of consortium PBR (and its characterization) for the degradation of pyrene from the 
Table 1 The effect on indigenous microflora and the ability of the consortium on pyrene degradation during microcosm studies

\begin{tabular}{|c|c|c|}
\hline $\begin{array}{l}\text { Experimental } \\
\text { sets }\end{array}$ & Experimental parameters & $\begin{array}{l}\text { Degradation } \\
(\%)\end{array}$ \\
\hline Set 1 & $\begin{array}{l}\text { Pristine, non-sterile soil amended with } 100 \mathrm{ppm} \text { pyrene, } 100 \mathrm{ppm} \text { fluoranthene, } 500 \mathrm{ppm} \text { naphthalene, } \\
250 \mathrm{ppm} \text { phenanthrene and } 5 \mathrm{ppm} \text { chrysene and consortium PBR }\end{array}$ & 85 \\
\hline Set 2 & Pristine, non-sterile soil amended with $100 \mathrm{ppm}$ pyrene and consortium PBR & 99 \\
\hline Set 3 & $\begin{array}{l}\text { Pristine, non-sterile soil amended with } 100 \mathrm{ppm} \text { pyrene, to determine the ability of indigenous microflora } \\
\text { for pyrene degradation }\end{array}$ & 39 \\
\hline Set 4 & $\begin{array}{l}\text { Polluted, non-sterile soil amended with } 100 \mathrm{ppm} \text { pyrene, } 100 \mathrm{ppm} \text { fluoranthene, } 500 \mathrm{ppm} \text { naphthalene, } \\
250 \mathrm{ppm} \text { phenanthrene and } 5 \mathrm{ppm} \text { chrysene and consortium PBR }\end{array}$ & 99 \\
\hline Set 5 & Polluted, non-sterile soil amended with $100 \mathrm{ppm}$ pyrene, and consortium PBR & 99 \\
\hline Set 6 & $\begin{array}{l}\text { Polluted, non-sterile soil amended with } 100 \mathrm{ppm} \text { pyrene, to determine the ability of indigenous microflora } \\
\text { for pyrene degradation }\end{array}$ & 48 \\
\hline Set 7 & $\begin{array}{l}\text { Pristine, sterile soil amended with } 100 \mathrm{ppm} \text { pyrene, } 100 \mathrm{ppm} \text { fluoranthene, } 500 \mathrm{ppm} \text { naphthalene, } 250 \mathrm{ppm} \\
\text { phenanthrene and } 5 \mathrm{ppm} \text { chrysene and consortium PBR }\end{array}$ & 86 \\
\hline Set 8 & Pristine, sterile soil amended with $100 \mathrm{ppm}$ pyrene and consortium PBR & 77 \\
\hline Set 9 & Pristine, sterile soil amended with $100 \mathrm{ppm}$ pyrene, to determine abiotic loss of pyrene & 3 \\
\hline Set 10 & $\begin{array}{l}\text { Polluted, sterile soil amended with } 100 \mathrm{ppm} \text { pyrene, } 100 \mathrm{ppm} \text { fluoranthene, } 500 \mathrm{ppm} \text { naphthalene, } 250 \mathrm{ppm} \\
\text { phenanthrene and } 5 \mathrm{ppm} \text { chrysene and consortium PBR }\end{array}$ & 85 \\
\hline Set 11 & Polluted, sterile soil amended with $100 \mathrm{ppm}$ pyrene, and consortium PBR & 75 \\
\hline Set 12 & Polluted, sterile soil amended with $100 \mathrm{ppm}$ pyrene, to determine abiotic loss & 1 \\
\hline
\end{tabular}

polluted sediments of Amlakhadi canal, Ankleshwar, Gujarat. The physicochemical parameters of Amlakhadi are shown in Table S1. From Table S1 it is clear that there is the presence of heavy metals in the sediments of the Amlakhadi canal. More than 1200 industrial units are manufacturing petroleum products, chemicals, pesticides, pharmaceuticals, bulk drugs, engineering, plastic and many other products and effluents from these industries are released into the Amlakhadi canal. The continual release of these effluents (for the last four decades) containing compounds of xenobiotic origin, have acclimatize the inhabitant microorganisms which have evolved the necessary resilient mechanisms for their metabolism. Hence it was a pertinent site to obtain the enriched bacterial community, having the inherent capacity to metabolize PAHs.

\section{Development of bacterial consortium PBR and bacterial identification}

The consortium PBR having pyrene catabolizing ability was developed through culture enrichment method in Bushnell-Haas medium amended with pyrene using sediments of Amlakhadi canal. With each consecutive transfer of the consortium, pyrene degradation efficiency has concurrently enhanced and stable growth of the constituent bacterial species was also observed. During the process of consortium enrichment, samples were intermittently withdrawn to assess the degradation efficiency and were simultaneously spread on different media as mentioned above to screen bacteria constituting the consortium. The distinct bacterial colonies with unique morphology were further purified and identified as Pseudomonas sp. ASDP1 (NCBI Accession No.: KU375114), Burkholderia sp. ASDP2 (KU375115) and Rhodococcus sp. ASDP3 (KU375116). All the three bacteria are well known for pyrene degradation (Juhasz and Naidu 2000). Figure 1 shows the degradation profile of each constituent individual culture of the consortium. It was evidently observed the incompetence of the individual bacterial species in pyrene degradation, where even after ten days 5, 14 and $18 \%$ of initial pyrene concentration was degraded by ASDP1, ASDP2 and ASDP3, respectively. However, nearly complete degradation of $100 \mathrm{ppm}$ of pyrene was observed within seven days by the consortium PBR comprising of above three species. Therefore, co-metabolism may play pivotal role in degradation of pyrene.

\section{Growth rate and effect of substrate concentration}

It is imperative to determine the load of a pollutant that can be degraded by defined number of microorganisms. In a polluted environment, there is a range of concentrations of different pollutants and microorganisms have different sensitivities towards the various concentrations of pollutants (Leahy and Colwell 1990; Boopathy 2000). In kinetic terms, there is always a threshold concentration below which the pollutants cannot be detected by particular numbers of organisms and above a particular concentration of pollutant; it will prove toxic to microorganisms (Doick et al. 2005; Okpokwasili and Nweke 2005). Moreover, it was generally observed that in certain confined range, as the concentration of pollutant increases, the rate of 
Fig. 1 Degradation of pyrene (100 ppm) by individual constituent pure cultures, combination of the pure cultures and consortium under optimized conditions $\left(37^{\circ} \mathrm{C}\right.$ and $\mathrm{pH} 7$, $150 \mathrm{rpm})$ in BHM. ASDP1: Pseudomonas sp. ASDP1, ASDP2: Burkholderia sp. ASDP2, ASDP3: Rhodococcus sp. ASDP3, PBR: Consortium

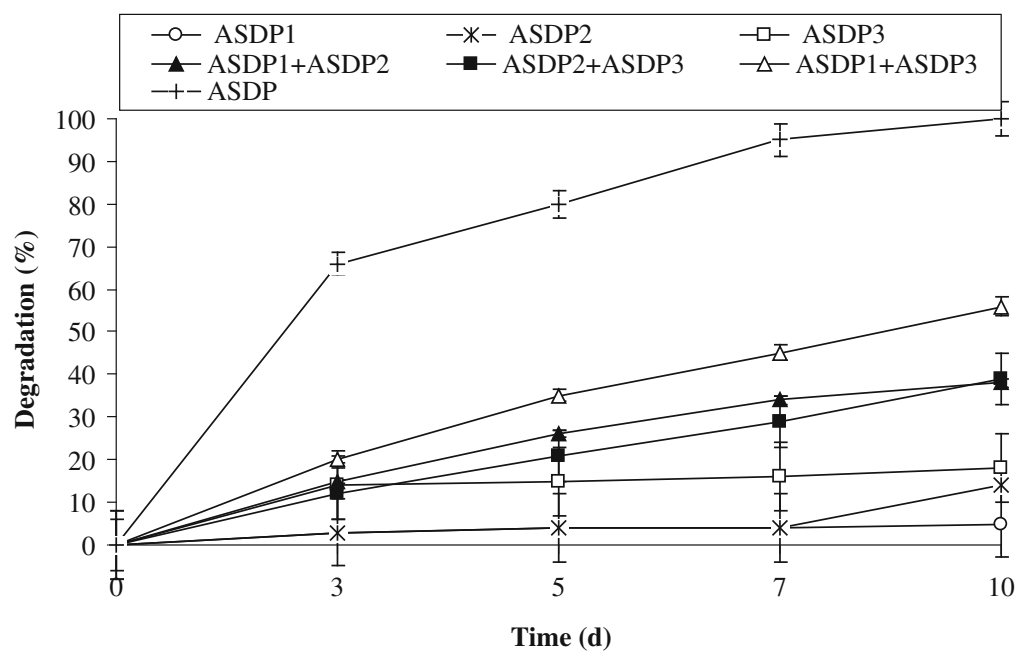

Fig. 2 Effect of pyrene concentrations on its degradation rate $\left(q_{\max }\right)$ and on growth rate $\left(\mu_{\max }\right)$ of the consortium at $37^{\circ} \mathrm{C}$ and $\mathrm{pH} 7$, $150 \mathrm{rpm}$ in BHM

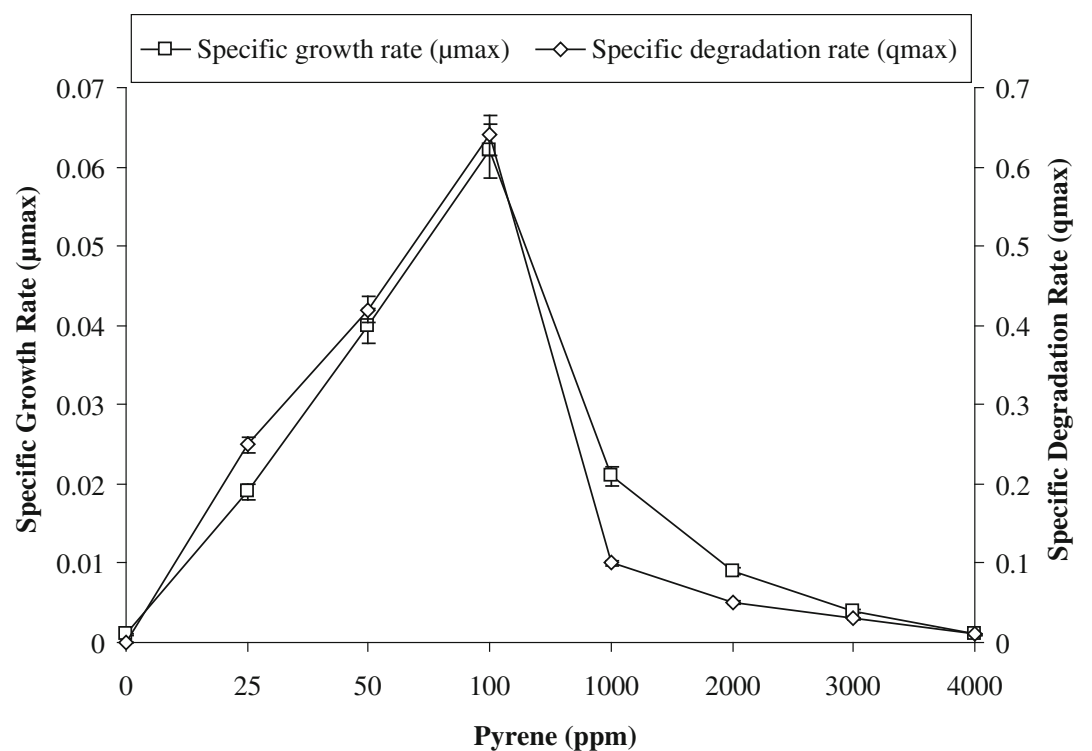

degradation of that pollutant also increases. This can be determined by kinetic parameters viz. specific growth rate $(\mu)$, specific degradation rate $(q)$ and half saturation rate constant $(k)$.

From Fig. 2, it was clear that 100 ppm of pyrene was efficiently degraded within 7 days as compared to higher concentrations. The degradation efficiency of PBR gradually decreases with increasing pyrene concentrations and it falls nearly 16-fold, where only $640 \mathrm{ppm}$ (i.e. 16\%) of 4000 ppm pyrene was degraded by the consortium after 7 days. The results from Fig. 2 further revealed that, the specific degradation rate $(q)$ and specific growth rate $(\mu)$, increases linearly with the increase in pyrene concentrations, in lower range of $25-100 \mathrm{ppm}$. However, both these rates subsequently decreased at higher concentrations from 1000 to $4000 \mathrm{ppm}$. Maximum growth rate $\left(\mu_{\max }\right)$, half saturation coefficient $\left(K_{S}\right)$ and maximum degradation rate $\left(q_{\max }\right)$ of pyrene for consortium PBR were $0.062 / \mathrm{h}, 6 \mathrm{mg} / \mathrm{L}$ and $14 \mathrm{mg} / \mathrm{L} / \mathrm{d}$, respectively. With the increase in pyrene concentration, the sharp fall in degradation as well as growth rates was observed (Fig. 2). The growth rate decreased nearly 3 -fold at $1000 \mathrm{ppm}(0.021 / \mathrm{h})$ and 62 -fold at $4000 \mathrm{ppm}(0.001 / \mathrm{h})$. Whereas the degradation rate correspondingly deceased nearly 3 -fold at $1000 \mathrm{ppm}(5.1 \mathrm{mg} /$ $\mathrm{L} / \mathrm{d})$ and 64-fold at $4000 \mathrm{ppm}(0.25 \mathrm{mg} / \mathrm{L} / \mathrm{d})$. Therefore, it could be assessed that, the degradation of pyrene was dependent on the growth of the consortium and it evidently suggested that the decrease in pyrene concentration is biologically mediated rather than abiotic loss. Further, the higher concentrations of pyrene were inhibitory and might be toxic to the consortium retarding the growth of the bacteria.

Thus, the results provided the significant implications about the substrate sensitivity of the consortium PBR, which prompted us to conduct further experimentation at 100 ppm of pyrene. It was observed that, the efficiency of 
xenobiotic degradation by microorganisms mostly dependent on the environmental conditions and different parameters needs to be studied precisely so as it can be applied further for large scale actual onsite or reactor scale remediation process. Hence, the effect of each significant factor for PAHs degradation was studied to enhance the degradation potential of the consortium PBR.

\section{Effect of temperature, $\mathrm{pH}$ and oxygen concentration}

Temperature is one of the important environmental and abiotic parameters. Biodegradation is also a chemical reaction, and enzymatic catalysis carried out by microorganisms generally lies in the optimum (growth) temperature range. Amlakhadi canal and its surrounding geographical region have relatively temperate climate with temperature ranging from 15 to $45^{\circ} \mathrm{C}\left( \pm 2{ }^{\circ} \mathrm{C}\right)$ was commonly observed during winter to summer, respectively. Therefore, the degradation experiments were performed between 30 and $50{ }^{\circ} \mathrm{C}$. The results in Fig. 3a suggest that a lower temperature is more favorable for optimum degradation of pyrene. At $37^{\circ} \mathrm{C}$ about $80 \%$ of $100 \mathrm{ppm}$ of pyrene was effectively degraded; however, the maximum degradation $(95 \%)$ by PBR could be obtained at $37{ }^{\circ} \mathrm{C}$ after 7 days. The results revealed the decreases in the degradation rate at higher temperature and the degradation rate nearly declined by 2.1 -fold at $50{ }^{\circ} \mathrm{C}$. Nearly all aerobic enzymes for the degradation of PAHs work optimally in the range $30-37^{\circ} \mathrm{C}$ (Patel et al. 2012a, b; Hamzah et al. 2011; Mukherjee and Roy 2013).

$\mathrm{pH}$ is another important factor in the biochemical reactions carried out by enzymes that catalyze the reactions. Figure $3 b$ demonstrates the effect of $\mathrm{pH}$ on the degradation of pyrene by PBR. It suggested that for better/efficient degradation of pyrene, lower $\mathrm{pH}$ was more effective. At $\mathrm{pH} 6.0,70 \%$ of $100 \mathrm{ppm}$ of pyrene was degraded within 7 days, while the maximum degradation (97\%) was observed at $\mathrm{pH} 7.0$. At higher $\mathrm{pH} 9.0$ nearly 1.8 fold decrease in degradation rate was observed. In various earlier studies it was observed that setting of $\mathrm{pH}$ to near neutrality has proven beneficial for the bioremediation of gasoline-contaminated soil, oily sludge in the soil and degradation of octadecane, naphthalene, and other PAHs, e.g. pyrene (Leahy and Colwell 1990; Verstraete et al.
Fig. 3 Effect of a temperature and $\mathbf{b} \mathrm{pH}$ on the degradation of pyrene by consortium PBR at $150 \mathrm{rpm}$ in BHM
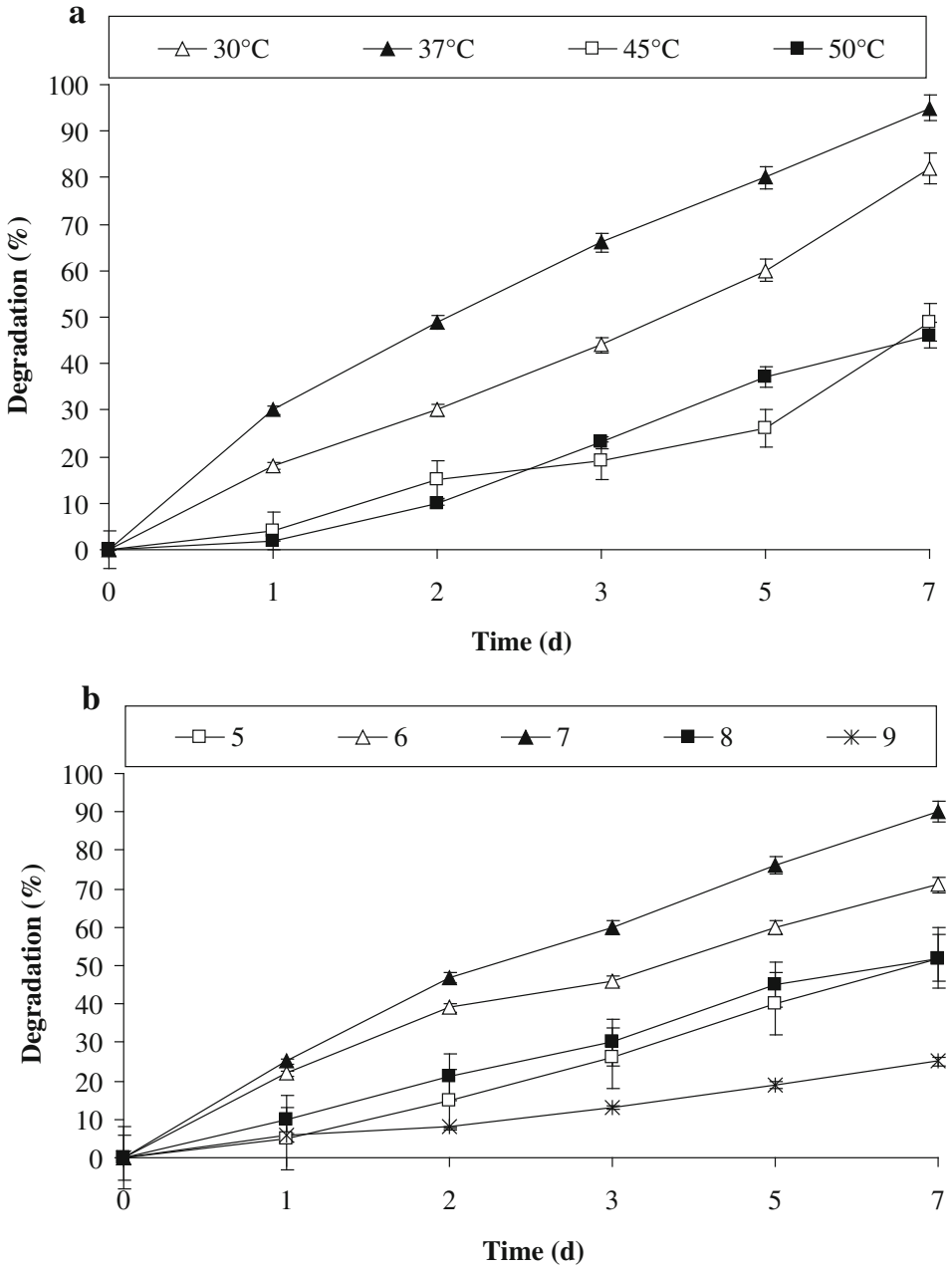
Fig. 4 Effect of various shaking and static conditions on the degradation of pyrene by consortium PBR at $37^{\circ} \mathrm{C}$ in BHM, pH 7.0

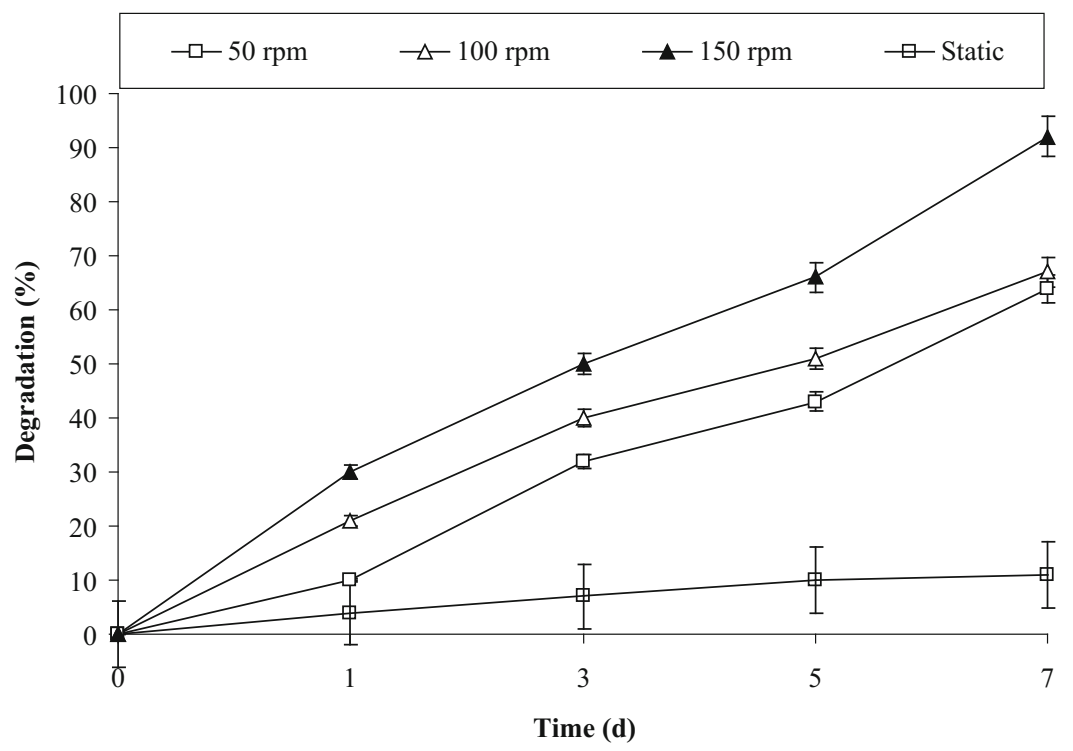

1976; Patrick and DeLaune 1977; Hambrick et al. 1980; Dibble and Bartha 1979). In a recent work, Ravanipour et al. (2015) proved that $\mathrm{pH} 6.8$ was better for the development and maintenance of bacterial consortia for the phenanthrene degradation in artificially contaminated soil. Pure culture study of degradation of pyrene by Rhodococcus sp. UW1 also indicated that, maximum degradation of pyrene and highest activity of dioxygenase system was found at $\mathrm{pH} 7.1$ and 7.2, respectively (Walter et al. 1991).

The multi-component monooxygenases and dioxygenases playing a significant role in the initial steps of PAHs degradation essentially required molecular oxygen (Leahy and Colwell 1990). Besides, oxygen is a primary requirement for the aerobic degradation of nutrients. The results from Fig. 4 support the above notion and reveal that environments, which lack molecular oxygen, did not support pyrene degradation, i.e. only $11 \%$ of pyrene was degraded by PBR after 7 days under static conditions. But as soon as, the oxygen concentration increases (i.e. at $50 / 100 \mathrm{rpm}$ of shaking) degradation rate enhanced by 6-fold; however, maximum degradation was observed under $150 \mathrm{rpm}$ with increase in 9-fold in metabolic activity of PBR for pyrene degradation. Moreover, with the increase in the shaking speed, the opportunity of contact between bacterial cells and PAHs also increases, which might enhance the rate of degradation.

Nevertheless, PAHs with 2-3 rings are observed to be degraded under anaerobic conditions at very slow rates, but there are very rare observations for the degradation of PAHs with more than three rings (Johnson et al. 2005). Proportional utilization of PAH carbon to natural organic carbon is 3 orders of magnitude higher during cooler months when water temperatures are low and dissolved oxygen (DO) percent saturation is higher and infusion of cooler, well-oxygenated water to the water column overlying contaminated sediments during summer stimulates PAH metabolism (Boyd et al. 2005). In the context of these observations, it was obvious that degradation of pyrene, which possesses four ring clusters, requires high dissolved oxygen concentration and in turn higher shaking conditions.

\section{Effect of organic carbon sources, intermediates and surfactants}

The availability of electron rich reduced substrates in the environment and the accessibility of PAHs to microorganisms (owing to their highly hydrophobic nature) are few significant factors that affect the degradation of these compounds. Figure 5a, b shows the effect of different compounds on pyrene degradation and it can be observed that both organic sources, peptone and yeast extract had negligible effect on pyrene degradation, while the rate of degradation decreased by 1.5- and 1.6-fold in the presence of glucose and ammonium nitrate, respectively. Similarly, upon providing phthalic acid and salicylic acid, the end products of the pyrene degradation (Seo et al. 2009), the degradation rate also decreased by 1.7 - and 2.75 -fold, respectively. It seems that both these compounds may inhibit the degradation pathway by feedback inhibition of degradation enzymes. The study further revealed the interesting results; it was observed that on providing sodium succinate (Fig. 5a), degradation rate was enhanced by 1.7 -fold and complete degradation of $100 \mathrm{ppm}$ of pyrene was obtained within 5 days. The positive effect of succinate could be related to the TCA cycle intermediate, which may provide direct utilization of the compound bypassing the rate-limiting steps in the pathway. 
Fig. 5 Effect of a various organic and inorganic sources and $\mathbf{b}$ glucose and intermediates on pyrene degradation by the consortium PBR under optimized conditions $\left(37^{\circ} \mathrm{C}\right.$ and $\mathrm{pH} 7,150 \mathrm{rpm}$ ) in BHM
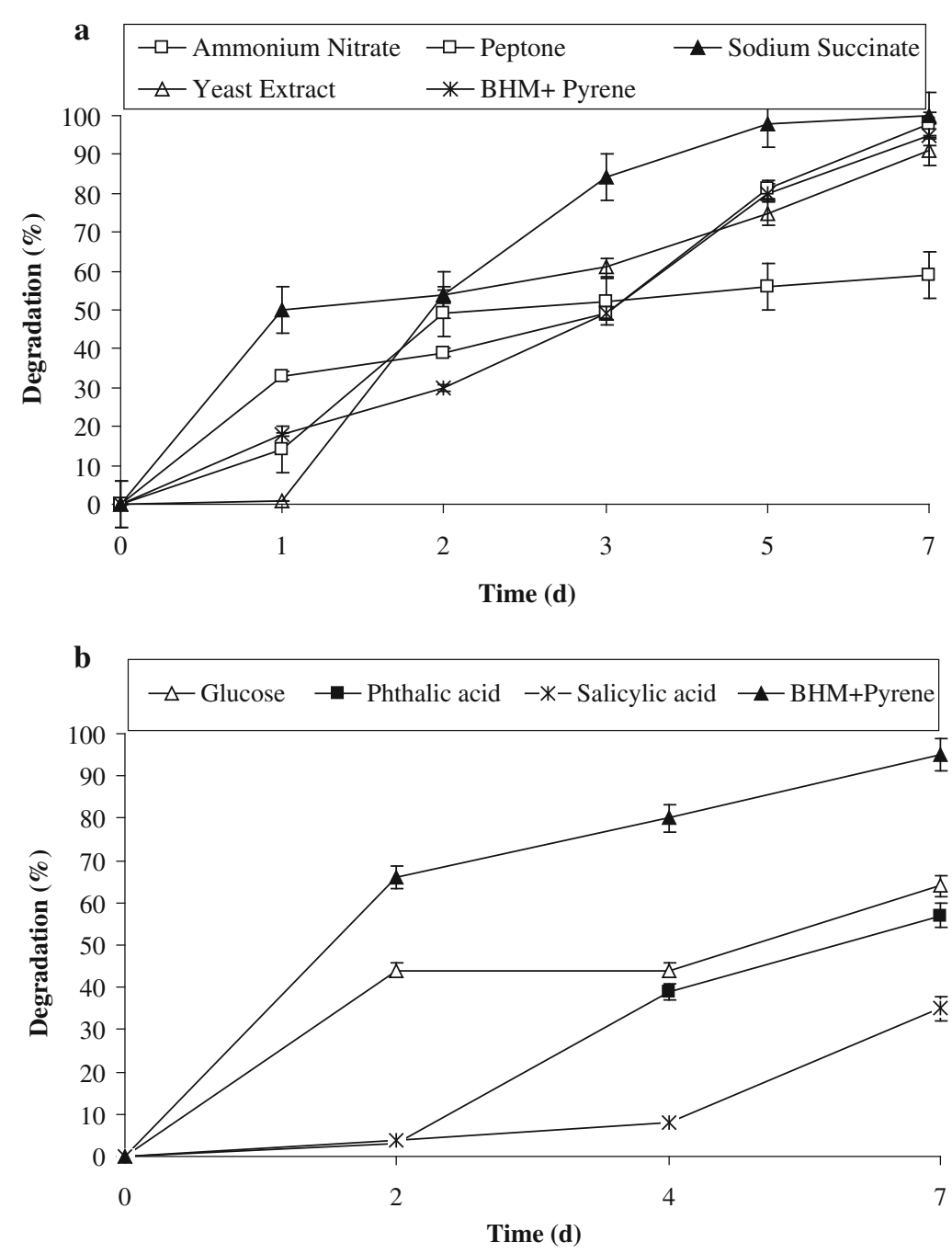

Fig. 6 Effect of different surfactants on pyrene degradation by the consortium PBR under optimized conditions $\left(37^{\circ} \mathrm{C}\right.$ and $\mathrm{pH} 7$, $150 \mathrm{rpm})$ in BHM

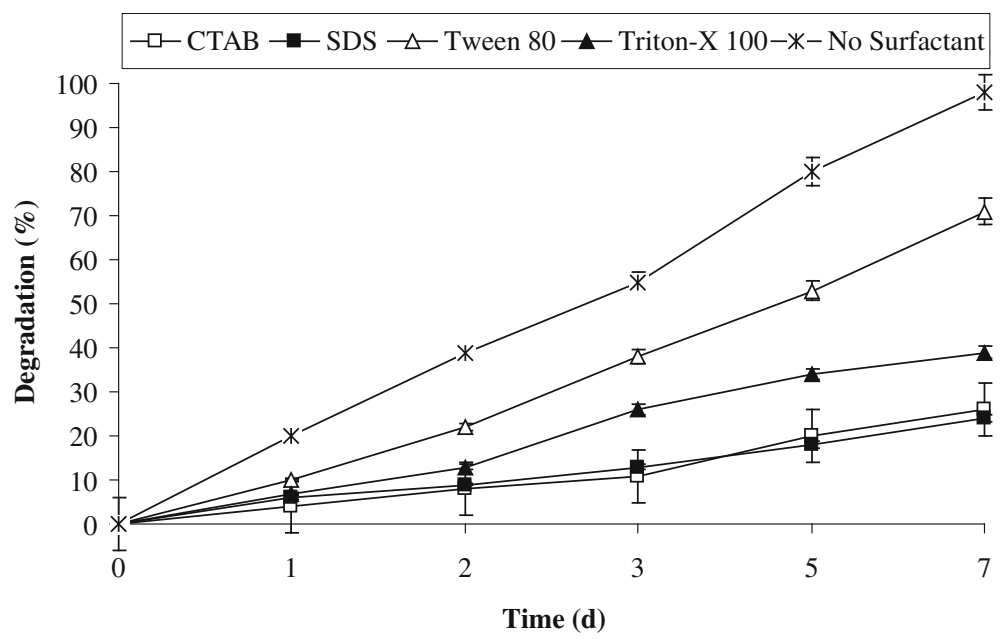

In the natural environment PAHs tend to sequester in sediments where they are out of reach of microbial degradation (Boopathy 2000). Their availability to the microorganism can be increased by supplementing the surfactants. The observed results showed that all the surfactants used in the study did not enhance degradation potential of the consortium. However, their supplementation decreased the pyrene degradation rate. Figure 6 
revealed a 3.8-fold decrease in the presence of CTAB, while the degradation rate was decreased by $4.1-, 1.4-$, and 2.5 -fold in the presence of SDS, Tween 80 , and Triton$\mathrm{X} 100$. The decrease in the degradation rate of pyrene by consortium on supplementing the surfactants is mainly due to preferential utilization of surfactant as carbon and energy source over pyrene. Few of the surfactants would be toxic to the consortium which has resulted in the decrease in the pyrene degradation (Shuttleworth and Cerniglia 1995; Mrozik et al. 2003; Pathak et al. 2009).

In our earlier studies, similar observations were made, where naphthalene degradation by Pseudomonas sp. HOB1 was not enhanced by addition of external surfactants (Pathak et al. 2009). In another study, Patel et al. (2012) also observed that external supplementation of surfactants did not enhance the degradation of phenanthrene by Pseudoxanthomonas sp. DMVP2. The anionic and cationic surfactants SDS and CTAB, respectively, decreased the phenanthrene degradation by consortium ASP (Patel and Madamwar 2013). These results additionally suggested that the strains involved in PAHs degradation might be producing bio-surfactant and further supplementation of surfactant may have negative effect on PAHs degradation (Pathak et al. 2009).

\section{Effect of inoculum size}

Though consortia may contain different PAH degrading bacteria, there is always one threshold of a number of organisms above which degradation occurs optimally and below which the rate of degradation is quite low (Okpokwasili and Nweke 2005). If the inoculum size was increased above the optimal level, there was no increase in degradation rate of pollutant as at greater inoculum size the organisms may rapidly reach in stationary phase of growth curve of microorganisms (Patel et al. 2012a; Abdelhay et al. 2008). In supporting the above notion, the results from Fig. 7 demonstrated that $5 \%(\mathrm{v} / \mathrm{v})$ inoculum was the optimum inoculum size for efficient degradation of pyrene. Below and above $5 \%$ inoculum size the rate of degradation decreased, the similar results were observed by Abdelhay et al. (2008).

\section{Effect of other hydrocarbons on pyrene degradation and simultaneous degradation of different PAHs}

Polluted ecosystems always consist of various mixtures of compounds in different concentrations. It is always important to assess the degradation potential of the consortium for their individual and simultaneous degradation of different pollutants. Though, simultaneous degradation of different compounds is a different issue from this where the developed consortia uses multiple strategies to degrade different compounds simultaneously. Therefore, a study has been designed to assess the potential of the consortium PBR for simultaneous degradation of the different PAHs and the effect of other hydrocarbons on the degradation of pyrene. It can be observed from Fig. 8 that chrysene and fluoranthene completely inhibited pyrene degradation, while it was decreased by 3.1-fold in the presence of naphthalene. The results further revealed that nearly $85 \%$ of initial concentration of the pyrene was degraded in the presence of benzene and toluene. Whereas on providing six different hydrocarbons together, $71 \%$ pyrene was degraded (Fig. 8). The study by Bacosa and Inoue (2015) showed that different consortia have different potentials for using PAHs as the sole carbon source. Their study also revealed that few consortia can degrade pyrene as the sole source of carbon. But other consortia required earlier exposure of PAHs for metabolism of pyrene.
Fig. 7 Effect of inoculum size on pyrene degradation by the consortium PBR under optimized conditions $\left(37^{\circ} \mathrm{C}\right.$ and $\mathrm{pH} 7,150 \mathrm{rpm})$ in BHM

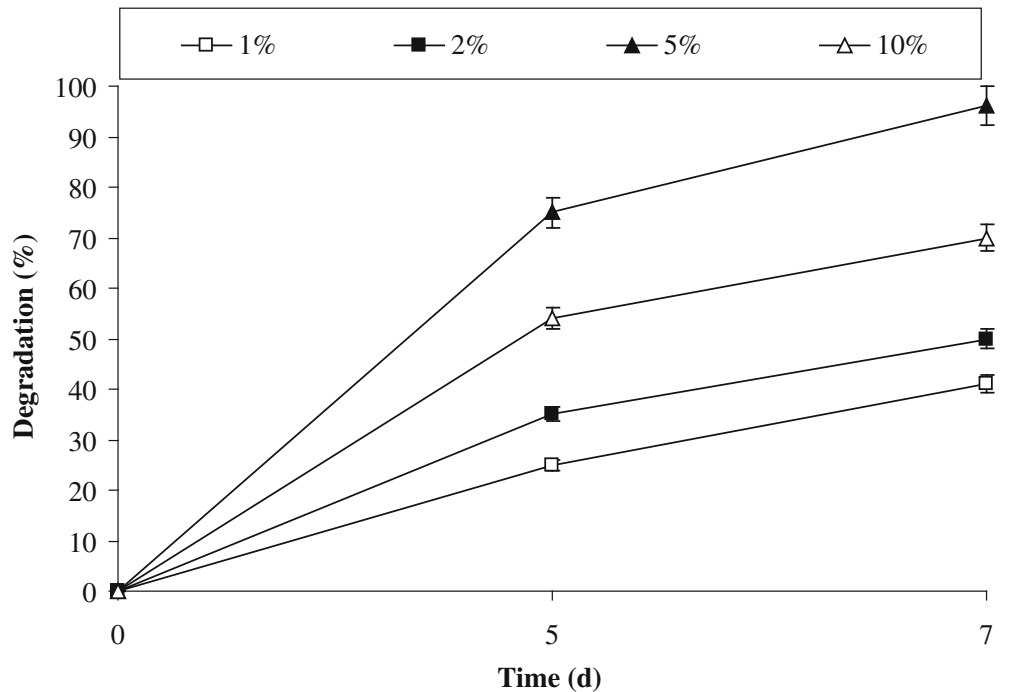

Time (d)

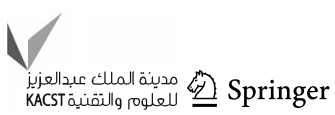


Fig. 8 Effect of different hydrocarbons on pyrene degradation by the consortium PBR under optimized conditions $\left(37^{\circ} \mathrm{C}\right.$ and $\mathrm{pH} 7$, $150 \mathrm{rpm})$ in BHM

Fig. 9 Simultaneous degradation of other hydrocarbons along with pyrene degradation by the consortium conditions $\left(37^{\circ} \mathrm{C}\right.$ and $\mathrm{pH} 7$, $150 \mathrm{rpm}$ ) in BHM PBR under optimized
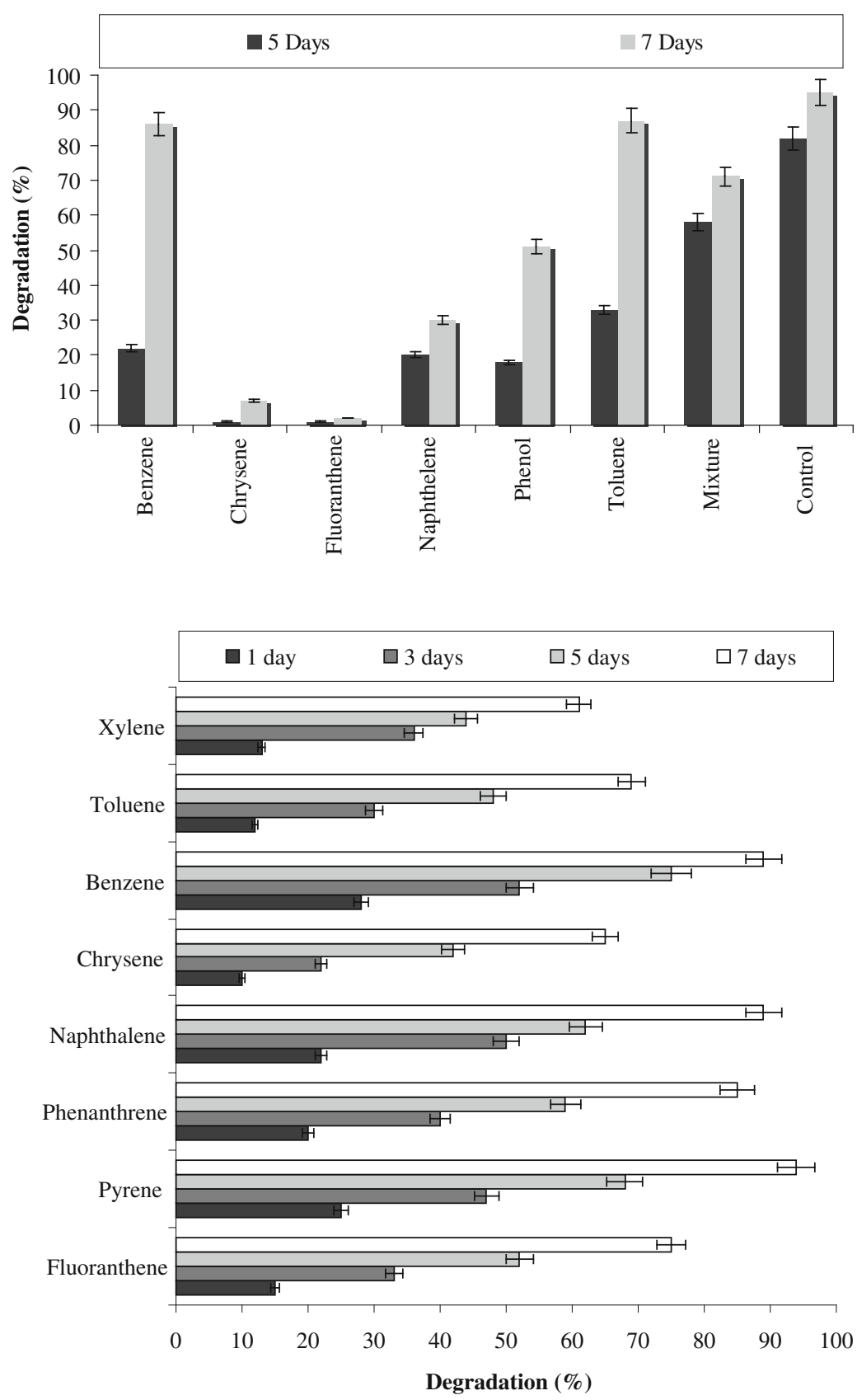

It is the most important and positive aspect of the developed consortium because during further studies like microcosm or reactor level the consortium must grow in presence of mixture of compounds. The decrease in the rate of degradation of pyrene in the presence of other hydrocarbons may be due to the toxicity of aromatic hydrocarbons like chrysene and fluoranthene. The toxicity is believed to be due to cell membrane disruption by aromatic hydrocarbons (Jacques et al. 2005). Moreover, due to structural similarity of many hydrocarbons, the bacterial oxygenases may utilize more than one hydrocarbon and cometabolize different substrates, however, at significantly low rates (Ascon-Cabrera and Lebeault 1993). The observed results are very similar with this notion because degradation of pyrene occurs in the presence of other hydrocarbons but at very low rates relative to control experiment where no other hydrocarbons are added.

Further, in a different study, the results from Fig. 9 revealed that above $60 \%$ of the all the PAHs (eight hydrocarbons) used in the experiments were degraded by the consortium. The degree of degradation of PAHs varies depending upon the test compound. Because the consortium was acclimatized with pyrene maximum degradation was observed with pyrene, followed by naphthalene $(89 \%)$, 
benzene $(89 \%)$ and phenanthrene $(85 \%)$. The higher rate of degradation of the all the compounds can be attributed to the co-metabolism. Co-metabolism is a very important phenomenon in nature where multiple compounds having similar structures can be degraded concurrently. Yuan et al. (2002) describes that degradation efficiency of microorganisms was more vigorous when acenaphthene, fluorene, phenanthrene, anthracene, and pyrene are present simultaneously compared to the rate of degradation when the PAHs are present individually because the presence of all five compounds provides more carbon source, or crossacclimation may enhance the rate of biodegradation.

\section{Effect of heavy metals}

Heavy metals are one of the major characteristic of polluted ecosystems such as polluted water bodies, aquifers and polluted sediments. They are inhibitory to microbial enzymes essential for different metabolic reactions and therefore inhibitory to the microbial growth (Chen et al. 2008). The study was performed to assess the effect of five heavy metals $\left(\mathrm{Pb}^{2+}, \mathrm{Hg}^{2+}, \mathrm{Cr}^{2+}, \mathrm{Zn}^{2+}\right.$ and $\left.\mathrm{Cd}^{2+}\right)$ at three different concentrations $(1,5$ and $10 \mathrm{mM})$ on the pyrene degradation. It is very apparent from Fig. 10 that pyrene degradation was affected in the presence of heavy metals and it significantly decreases at higher concentrations. The results revealed surprising observations, that pyrene degradation was affected severely in the presence of chromium, zinc and cadmium than lead and mercury. The degradation efficiency progressively decreased as the concentration of the heavy metals increased. Nearly $35 \%$ degradation was observed after seven days in the presence of chromium, zinc and cadmium at $1 \mathrm{mM}$ concentration each, while at the same concentration about more than $50 \%$ degradation was observed in the presence of lead and mercury.

The study also revealed another significant observation that the consortium was more resistant towards mercury, i.e. at higher concentration $(10 \mathrm{mM})$ nearly $30 \%$ pyrene was degraded after seven days, which was less than $10 \mathrm{mM}$ for another four heavy metals under similar conditions. Moreover, Figure S1 shows the relationship between percent growth retardation by different concentrations of heavy metals which was measured as described by Pepi et al. 2008. $\mathrm{EC}_{50}$ values represent the $50 \%$ reduction in the growth of the consortium at the different concentrations of heavy metals. For the consortium of pyrene degradation the EC50 for $\mathrm{Pb}^{2+}, \mathrm{Hg}^{2+}, \mathrm{Cr}^{2+}, \mathrm{Zn}^{2+}$ and $\mathrm{Cd}^{2+}$ is 6, 5, 6.9, 5.2 and $5.4 \mathrm{mM}$, respectively. The high tolerance to heavy metals may be due to production of bio-surfactant by the consortium (Sandrin et al. 2000) or precipitation of heavy metals by phosphate and sulfate of the medium (Patel et al. 2012b; Hughes and Poole 1991). At higher concentrations lead, mercury and cadmium were precipitated and therefore may not retard the degradation of test PAHs.

\section{Degradation profile of pyrene and stoichiometry}

The competence of the consortium for pyrene degradation and its degradation pattern was studied through HPLC. The chromatogram of intact pyrene showed a single major peak at retention time of $6.8 \mathrm{~min}$ (Fig. 11a). Degradation of pyrene by consortium PBR can be observed by the gradual decrease in the peak of pyrene from $250 \mathrm{mAU}$ ( 0 day) to
Fig. 10 Effect of different heavy metals on pyrene degradation by the consortium PBR under optimized conditions $\left(37^{\circ} \mathrm{C}\right.$ and $\mathrm{pH} 7$, $150 \mathrm{rpm}$ ) in BHM

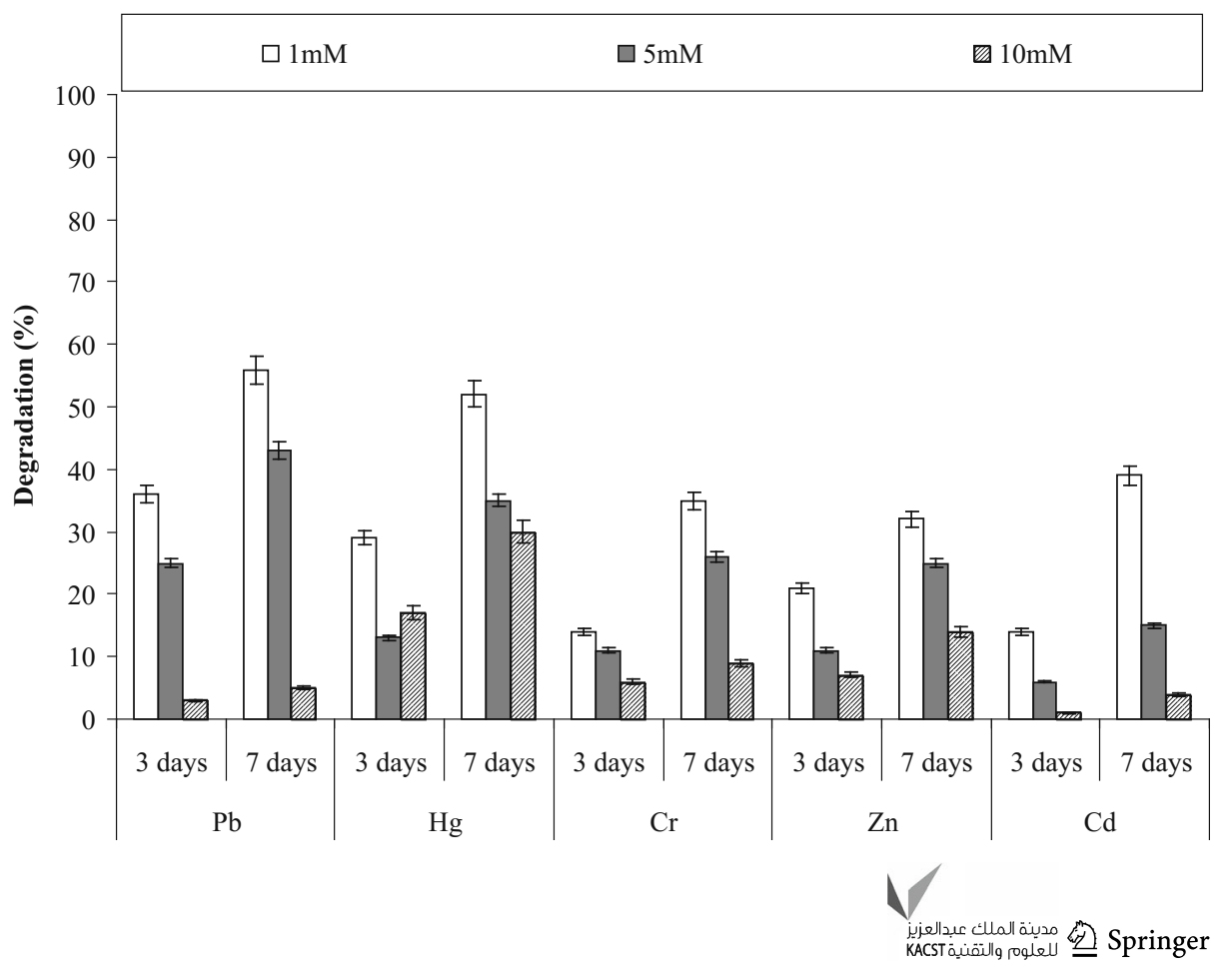


Fig. 11 HPLC chromatogram of $\mathbf{a}$ intact pyrene, $\mathbf{b}$ degraded intermediates after 3 days and c degraded intermediates after 7 days

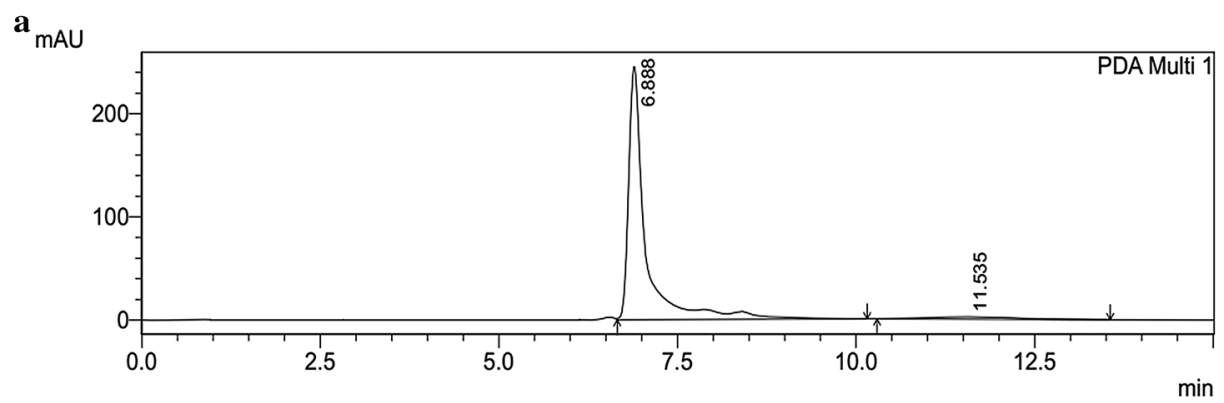

1 PDA Multi 1/254nm 4nm

b

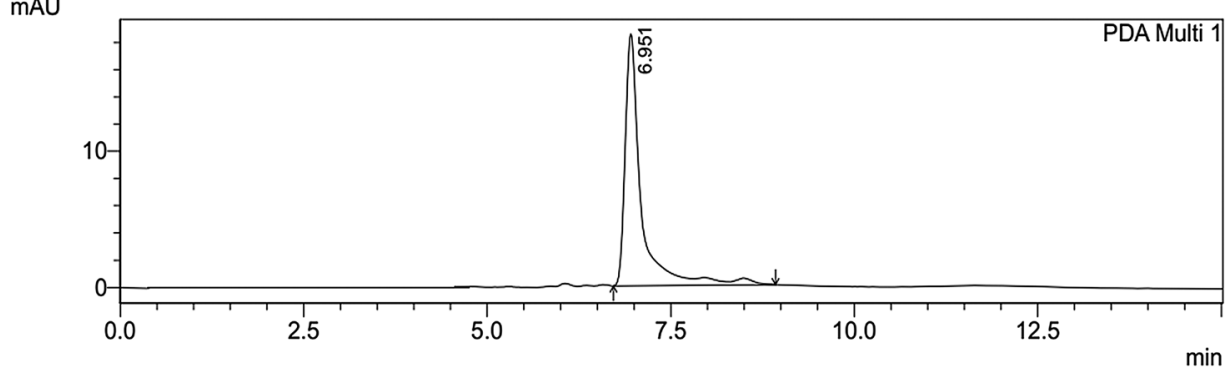

1 PDA Multi 1/254nm 4nm

$\mathbf{c}_{\mathrm{mAU}}$

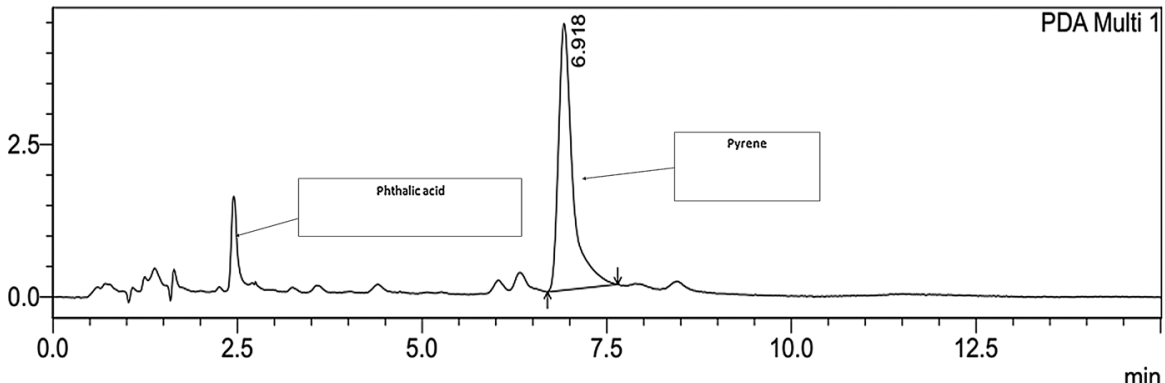

1 PDA Multi 1/254nm 4nm

$3.5 \mathrm{mAU}$ (7 days) at retention time near $6.8 \mathrm{~min}$. The observed results evidently indicated the formation of phthalic acid, having the retention time of $2.5 \mathrm{~min}$ (Fig. 11b, c). Therefore, it can be postulated that pyrene was degraded through phthalic acid pathway by the consortium PBR and the proposed pathway is as depicted in Fig. 12.

The stoichiometric relation between pyrene and phthalic acid was established and the results indicated that, from $0.4 \mathrm{mM}$ of pyrene, $0.003 \mathrm{mM}$ of phthalic acid was produced through synergistic metabolism of consortial species. That is, the stoichiometric ratio of nearly 1:100 between pyrene and phthalic acid can be postulated for $100 \mathrm{ppm}$ of initial pyrene concentration and can be correlated from HPLC chromatogram of degraded products of pyrene (Fig. 11a, c). Therefore, the results evidently suggested that phthalic acid is not a dead end product of bacterial consortial metabolism, because the ratio of pyrene:phthalic acid was at much lower side. If it could have been a dead end product, the expected ratio would have higher value. Moreover, from Fig. 11c, the HPLC chromatogram of pyrene degradation revealed the emergence of other peaks at different retention time, along with major peak of phthalic acid. The difference between peaks of native pyrene molecule and phthalic acid was comparatively higher which clearly suggested that phthalic acid was not accumulated in the medium and effectively being metabolized by consortium PBR.

This is an important observation for the complete mineralization of pyrene, as Krishnan et al. (2004) observed the accumulation of phthalic acid while monitoring the degradation of phenanthrene by Pseudomonas sp. strain PP2, which have similar structural properties with pyrene. This implied the importance of consortium, where two or more microorganisms synergistically degrade and metabolize the xenobiotic compounds which is recalcitrant for complete degradation by single organism. 
Fig. 12 Proposed pathway for degradation of Pyrene by the consortium PBR under optimized conditions<smiles>c1cc2ccc3cccc4ccc(c1)c2c34</smiles>

Pyrene

(RT: $6.8 \mathrm{~min})$

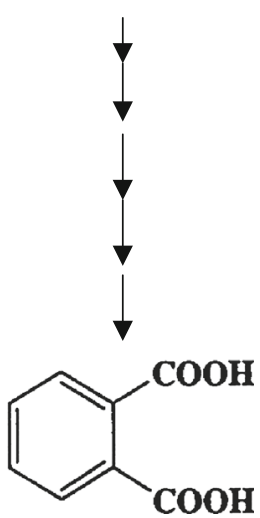

Phthalic acid

(RT $2.5 \mathrm{~min}$ )

Ring Cleavage

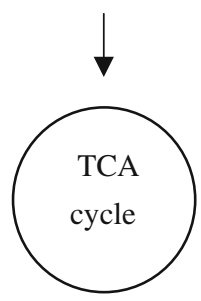

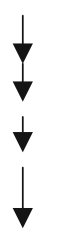

\section{Microcosm studies}

The microcosm studies provide an insightful observation about the competence of the consortium PBR for pyrene and other PAHs degradation under soil system and in the presence of the native microflora of polluted and pristine soils. Results from Table 1 evidently suggested that indigenous microflora of the polluted and pristine soils can degrade $39 \%$ of the pyrene without augmentation of consortium PBR whereas augmentation increases the degradation of pyrene in polluted and pristine soil to $99 \%$. This indicates the ability of developed consortium to work exclusively in presence of components of pristine soil as well as polluted indigenous which reveal the high efficiency of PBR consortium and reveal positive effect of augmentation of PBR consortium. Also the abiotic loss of PAH is negligible in presence of sterile polluted and pristine soil. It can be noted here that in sterile polluted and pristine soils the degradation occurs at 75 and $77 \%$, respectively, as compared to $99 \%$ degradation in both nonsterile polluted and pristine soils, which indicates the aid of indigenous microflora for the degradation by PBR consortium. Thus, indigenous microflora also works in cooperation with consortium to increase the degradation rate of pyrene. Also the degradation of pyrene was higher in the presence of non-sterile polluted samples as compared to sterile polluted samples. The $\lambda_{\max }$ for pyrene in $70 \% \mathrm{ACN}$ was $340 \mathrm{~nm}$ and for degradation calculation the O.D. at this wavelength was taken into consideration. But due to the cyclic structure and multiple benzene rings, pyrene has a complex absorption spectrum in the UV region that is from 200 to $400 \mathrm{~nm}$. Thus, consortium PBR is highly efficient in degrading pyrene in microcosm and may be applicable for the macrocosm and reactor scale study.

\section{Conclusion}

The study revealed the effectiveness of developed consortium PBR for pyrene degradation, where it was metabolized as a sole source of carbon and energy through the phthalic acid pathway. The competence of the consortium was revealed by the observations that it individually and simultaneously degraded six different hydrocarbons other than pyrene without supplementing any additional nutrient in BHM. Owing to the growth of consortium and degradation of pyrene in presence of other PAHs and heavy metals, low requirements like nutritional additives and surfactants and successful working in simulated microcosms, the developed consortium is indeed an efficient consortium and can be further used for macrocosm and reactor scale studies.

Acknowledgements The authors acknowledge Department of Biotechnology (DBT), Ministry of Science and Technology, New Delhi, India, for the financial support in form of Centre of Excellence and Innovations in Biotechnology (CEIB) (BT/01/CEIB/09/V/05).

\section{Compliance with ethical standards}

Conflict of interest The authors declare that they have no conflict of interest in the publication.

Open Access This article is distributed under the terms of the Creative Commons Attribution 4.0 International License (http:// creativecommons.org/licenses/by/4.0/), which permits unrestricted use, distribution, and reproduction in any medium, provided you give appropriate credit to the original author(s) and the source, provide a link to the Creative Commons license, and indicate if changes were made.

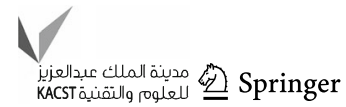




\section{References}

Abdelhay A, Magnin JP, Gondrexon N, Baup S, Willison J (2008) Optimization and modeling of phenanthrene degradation by Mycobacterium sp. 6PY1 in a biphasic medium using response-surface methodology. Appl Microbiol Biotechnol 78:881-888

Ascon-Cabrera M, Lebeault JM (1993) Selection of xenobioticdegrading microorganisms in a biphasic aqueous-organic system. Appl Environ Microbiol 59:1717-1724

Atlas RM, Hazen TC (2011) Oil Biodegradation and Bioremediation: a tale of the Two Worst Spills in US History. Environ Sci Technol 45(16):6709-6715

Ausubel FM, Brent R, Kingston RE, Moore DD, Seidman JA, Smith JG, Struhl DJ (1997) Current protocols in molecular biology. Wiley, New York (Unit 24)

Bacosa and Inoue (2015) Polycyclic aromatic hydrocarbons (PAHs) biodegradation potential and diversity of microbial consortia enriched from tsunami sediments in Miyagi. J Hazard Mater 283(2015):689-697

Bacosa HP, Suto K, Inoue C (2013) Degradation potential and microbial community structure of heavy oil-enriched microbial consortia from mangrove sediments in Okinawa, Japan. J Environ Sci Health A 48:1-12

Boopathy R (2000) Factors limiting bioremediation technologies. Bioresour Technol 74:63-67

Boyd TJ, Montgomery MT, Steele JK, Pohlman JW, Reatherford SR, Spargo BJ, Smith DC (2005) Dissolved oxygen saturation controls PAH biodegradation in freshwater estuary sediments. Microbiol Ecol 49:1-10

Chen Y, Cheng JJ, Creamer KS (2008) Inhibition of anaerobic digestion process: a review. Bioresour Technol 99:4044-4064

Desai C, Madamwar D (2007) Extraction of inhibitor-free metagenomic DNA from polluted sediments, compatible with molecular diversity analysis using adsorption and ion-exchange treatments. Bioresour Technol 98(4):761-768

Dibble JT, Bartha R (1979) Effect $f$ environmental parameters on the biodegradation of oil sludge. Appl Environ Microbiol 37:729-739

Doick KJ, Klingelmann E, Burauel P, Jones KC, Semple KT (2005) Long term fate of polychlorinated biphenyls and polycyclic aromatic hydrocarbons in agricultural soil. Environ Sci Techn 39:3663-3670

Ghosh I, Jasmin J, Mukherji S (2014) Biodegradation of pyrene by Pseudomonas aeruginosa strain RS1 isolated from refinery sludge. Bioresour Technol 166:548-558

Hambrick GA, DeLaune RD, Patrick WH Jr (1980) Effect of estuarine sediment $\mathrm{pH}$ and oxidation-reduction potential on microbial hydrocarbon degradation. Appl Environ Microbiol 40:365-369

Hamzah A, Tavakoli A, Rabu A (2011) Detection of toluene degradation in bacteria isolated from oil contaminated soils. Sains Malays 40(11):1231-1235

Haritash AK, Kaushik CP (2009) Biodegradation aspects of Polycyclic Aromatic Hydrocarbons (PAHs): a review. J Hazard Mater 169:1-15

Ho Y, Jackson M, Yang Y, Mueller JG, Pritchard PH (2000) Characterization of fluoranthene- and pyrene-degrading bacteria isolated from PAH-contaminated soils and sediments and comparison of several Sphingomonas spp. J Ind Microbiol 2:100-112

Hughes MN, Poole RK (1991) Metal speciation and microbial growth - the hard (and soft) facts. J Gen Microbiol 137:725-734

Jacques RJS, Santos EC, Bento FM, Peralba MCR, Selbach PA, Sá ELS, Camargo FAO (2005) Anthracene biodegradation by
Pseudomonas sp. isolated from a petrochemical sludge land farming site. Int Biodeterior Biodegrad 56:143-150

Johnson AR, Wick LY, Harms H (2005) Principles of microbial PAHdegradation in soil. Environ Pollut 133:71-84

Juhasz AL, Naidu R (2000) Bioremediation of high molecular weight polycyclic aromatic hydrocarbons: a review of the microbial degradation of benzo[ $\alpha]$ pyrene. Inter Biodeter Biodegrad 45:57-88

Kathuria V (2007) Informal regulation of pollution in a developing country: evidence from India. Ecolo Econ 63:403-417

Krishnan S, Prabhu Y, Phale PS (2004) $o$-Phthalic acid, a dead end product in one of two pathways of phenanthrene degradation in Pseudomonas sp. strain PP2. Indian J Biochem Biophys 41:227-232

Kumar A, Munjal A, Sawhney R (2011) Crude oil PAH constitution, degradation pathway and associated bioremediation microflora: an overview. Inter J Environ Sci 1(7):1420-1439

Leahy JL, Colwell RR (1990) Microbial degradation of hydrocarbons in the environment. Microbiol Rev 54:305-315

Mrozik A, Piotrowska-Seget Z, Labuzak S (2003) Bacterial degradation and bioremediation of polycyclic aromatic hydrocarbons. Polish J Environ Stud 12(1):15-25

Mukherjee P, Roy P (2013) Copper enhanced monooxygenase activity and FT-IR spectroscopic characterisation of biotransformation products in trichloroethylene degrading bacterium: Stenotrophomonas maltophilia PM102. BioMed Res Int 2013:1-9 Article ID 723680

Okpokwasili GC, Nweke CO (2005) Microbial growth and substrate utilization kinetics. Afr J Biotechnol 5:305-317

Patel V, Madamwar D (2013) Biodegradation of phenanthrene in bioaugmented microcosm by consortium ASP developed using coastal sediment of Alang-Sosiya ship breaking yard, Gujarat. Mar Pollut Bull 74:199-207

Patel V, Cheturvedula S, Madamwar D (2012a) Phenanthrene degradation by Pseudoxanthomonas sp. DMVP2 isolated from hydrocarbon contaminated sediment of Amlakhadi canal, Gujarat, India. J Hazard Mater 201-202:43-51

Patel V, Jain S, Madamwar D (2012b) Naphthalene degradation by bacterial consortium (DV-AL) developed from Alang-Sosiya ship breaking yard, Gujarat, India. Bioresour Technol 107:122-130

Pathak H, Kantharia D, Malpani A, Madamwar D (2009) Naphthalene degradation by Pseudomonas sp. HOB1: in vitro studies and assessment of naphthalene degradation efficiency in simulated microcosms. J Hazard Mater 166:1466-1473

Pathak H, Patel S, Rathod M, Chauhan K (2011) In vitro studies on degradation of synthetic dye mixture by Comamonas sp. VSMH2 and evaluation of its efficacy using simulated microcosm. Bioresour Technol 102:10391-10400

Patrick WH Jr, DeLaune RD (1977) Chemical and biological redox systems affecting nutrient availability in coastal wetlands. Geosci Man 18:131-137

Pepi M, Heipieper HJ, Fischer J, Ruta M, Volterrani M, Focardi SE (2008) Membrane fatty acids adaptive profile in the simultaneous presence of arsenic and toluene in Bacillus sp. ORAs2 and Pseudomonas sp. ORAs5 strains. Extremophiles 12:343-349

Ravanipour M, Kalantary RR, Mohseni-Bandpi A, Esrafili A, Farzadkia M, Hashemi-Najafabadi S (2015) Experimental design approach to the optimization of PAHs bioremediation from artificially contaminated soil: application of variables screening development. J Environ Heal Sci Eng 13:22

Sandrin TR, Chech AM, Maier RM (2000) A Rhamnolipid biosurfactant reduces cadmium toxicity during naphthalene biodegradation. Appl Environ Microbiol 66:4585-4588

Seo J, Keum Y, Li QX (2009) Bacterial degradation of aromatic compounds. Inter J Environ Res Public Health 6:278-309 
Shuttleworth KL, Cerniglia CE (1995) Environmental aspects of PAH biodegradation. Appl Biochem Biotechnol 54:291-302

Verstraete WR, Vanloocke R, De Borger, Verlinde A (1976) Modelling of the breakdown and the mobilization of hydrocarbons in unsaturated soil layers. In: Sharpley JM, Kaplan AM (ed) Proceedings of the 3rd international biodegradation symposium. Applied Science Publishers Ltd., London, pp 99-112

Walter U, Beyer M, Klein J, Rehm HJ (1991) Degradation of pyrene by Rhodococcus UW1. Appl Microbiol Biotechnol 34:671-676
Wang BJ, Lai QL, Cui ZS, Tan TF, Shao ZZ (2008) A pyrenedegrading consortium from deep-sea sediment of the West Pacific and its key member Cycloclasticus sp P1. Environ Microbiol 10(8):1948-1963

Yuan SY, Shiung LC, Chang BV (2002) Biodegradation of polycyclic aromatic hydrocarbons by inoculated microorganisms in soil. Bull Environ Contam Toxicol 69:66-73 